\title{
Single Beam Z-Scan Measurement of Nonlinear Refractive Index of Crude Oils
}

\author{
Adeleh Granmayeh Rad \\ Department of Physics, Faculty of Sciences, Roudehen Branch, Islamic Azad University, Roudehen, Iran \\ Email: granmayeh@riau.ac.ir
}

Received 30 November 2013; revised 29 December 2013; accepted 27 January 2014

Copyright (C) 2014 by author and Scientific Research Publishing Inc.

This work is licensed under the Creative Commons Attribution International License (CC BY). http://creativecommons.org/licenses/by/4.0/

(c) (;) 0 pen Access

\begin{abstract}
Nonlinear properties of two different crude oils from west-south Iran reservoirs have been investigated using the single beam Z-scan technique. The nonlinear refractive indices of the samples were measured by use of diode laser in the $\mathrm{CW}$ regime and at the wavelength $660 \mathrm{~nm}$. The experiment results showed that the samples have large and negative refractive index nonlinear refraction coefficient. These results showed that the crude oil has significant nonlinear properties and it could be a candidate for photonic and nonlinear optical devices and also this information can be used in petroleum science and oceanology and etc.
\end{abstract}

\section{Keywords}

Crude Oil; Z-Scan Method; Nonlinear Refractive Index

\section{Introduction}

By development of laser technology, the interest of finding materials with large nonlinear properties has been increased intensively, due to the numerous and variable applications in various fields such as telecommunications, optical data storage, photonic devices such as optical limiter [1]-[8].

The single beam Z-scan method introduced by Mansour Sheik-Bahae [9] [10] is an effective and simple technique for determining the nonlinear absorption and refraction coefficients, and it has been used widely for determining the nonlinear characteristics of different materials.

In this method, sample is scanned by moving through the focal plane of a tightly focused laser beam that its intensity is enough for accessing nonlinearities in a sample.

As the sample is moving through the focal point of the laser beam, by monitoring transmittance changes of the sample in the far field, nonlinear refractive and nonlinear absorption coefficients are measured by a closed and open aperture, respectively. 
However, this method is simple in principle, in practice because of fluctuations of the laser beam and the loss of detector due to both nonlinear and linear process, sensitivity is compromised to overcome these limitations, using a resource arm is suggested and also additional modifications have been proposed [11].

Crude oil is the term for "unprocessed" oil which is also known as petroleum. Petroleum is a mixture of a very large number of different hydrocarbons. The most commonly found molecules are alkanes (linear or branched), cycloalkanes, aromatic hydrocarbons, or more complicated chemicals like asphaltenes. The oil samples used for this experiment were collected from two different Iran oil reservoirs named Azadegan and Soroush; their API gravity measured is 20 and 22 degree, respectively which are considered as heavy oils.

In this paper, we have demonstrated the nonlinear characteristic of two different crude oils from Iran oil reservoirs-Azadegan and Soroush oil reservoirs and we have measured the nonlinear refraction coefficients using the single beam Z-scan technique at 660 excitation wavelength.

\section{Experiment}

The sample of oils were collected from two different Iran oil reservoirs in west south of Iran and Persian GulfAzadegan and Soroush oils. The samples has been weathered for two weeks in the room temperature. At first, spectral absorbance of the samples were measured by use of an UV-VIS spectrophotometer that has been shown in Figure 1.

Furthermore, the linear absorption coefficient of the samples was measured by the conventional method, BirLmabert that defines on the basis of $\alpha=-(1 / l) \ln \left(I_{0} / I\right)$ in the linear regime of the experiment.

The experimental set up for determining the nonlinear properties is shown in Figure 2. The experiment was carried out at room temperature and a CW diode laser operating at $660 \mathrm{~nm}$ was used as a light source, the laser beam after crossing over two lenses focused onto the sample by a lens of $28.5 \mathrm{~cm}$ focal length. The sample consisted of a pair of quartz glasses and crude oil and it was moved along the z-axis. The light transmittance was measured by a detector as a function of the sample position. At the focus point the power output of the laser beam was measured to be $90.7 \mathrm{~mW}$. The laser spot size at the focus was measured to be $\omega_{0}=21.1 \mu$.

\section{Results and Discussion}

The linear UV-VIS absorbance spectrum of Azadegan and Soroush crude oil is presented in Figure 1. As it can be seen in this figure, both samples present an absorbance peak at $552 \mathrm{~nm}$ but absorbance peak for Azadegan sample can be considerable.

The result of typical z scan normalized transmittance measurement for the samples are shown in "Figure 3".

The nonlinear refractive index can be calculated by fitting the normalized transmittance data to the closed aperture formula that given by Sheik Bahaei et al.

$$
T(z, \Delta \phi)=1-\frac{4 \Delta \phi_{0} x}{\left(x^{2}+1\right)\left(x^{2}+9\right)}
$$

where $\Delta \phi_{0}$ is the on-axis phase shift at the focus, which defines by the following equation:

$$
\Delta T_{p-v} \approx 0.406(1-s)^{0.25}\left|\Delta \phi_{0}\right|
$$

The $\Delta T_{p-v}$ can be defined as the difference between the normalized peak and valley transmittances and $S$ is linear transmittance of the aperture that is given by:

$$
S=1-\exp \left(-2 r_{a}^{2} / w_{a}^{2}\right)
$$

where $r_{a}$ is the radius of the aperture and $w_{a}$ is the beam radius at the aperture. Nonlinear refractive index, $\mathrm{n}_{2}$ can be calculated using simple expression:

$$
n_{2}=\frac{\Delta \phi_{0}}{k I_{0} L_{e f f}}
$$

Here $k, I_{0}, L_{\text {eff }}$ are wave number, peak intensity within the sample at the focus and the effective thickness:

$$
L_{\text {eff }}=\left[1-\exp \left(-\alpha_{0} L\right)\right] / \alpha_{0}
$$




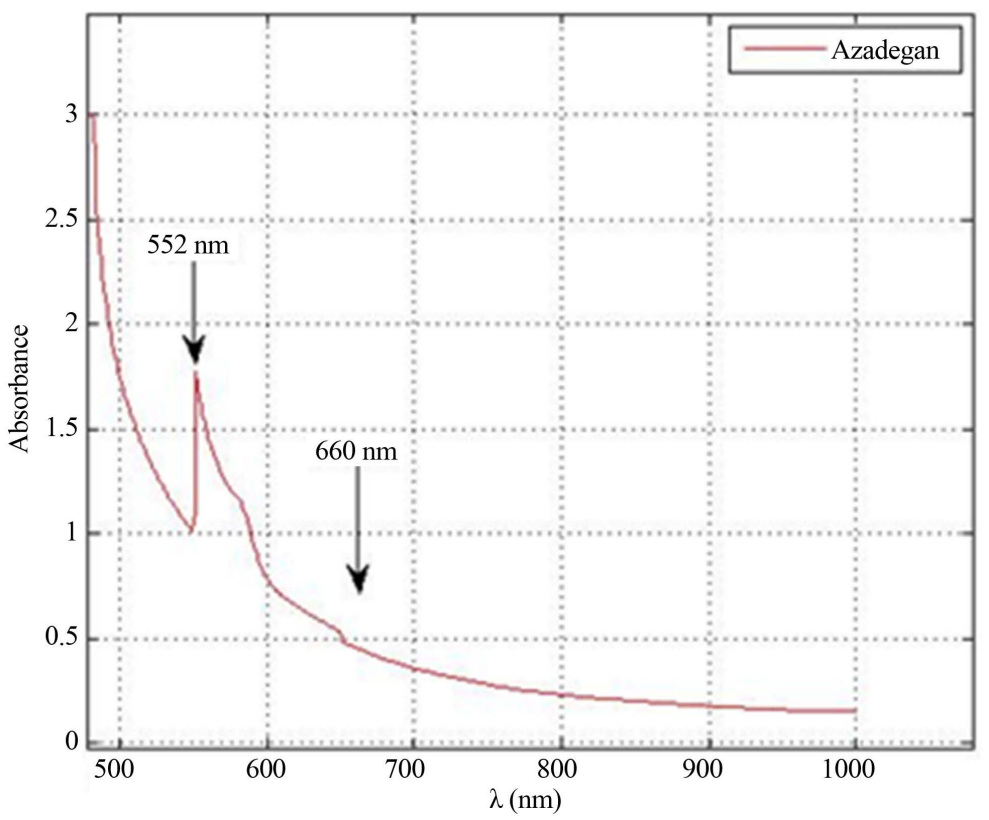

(a)

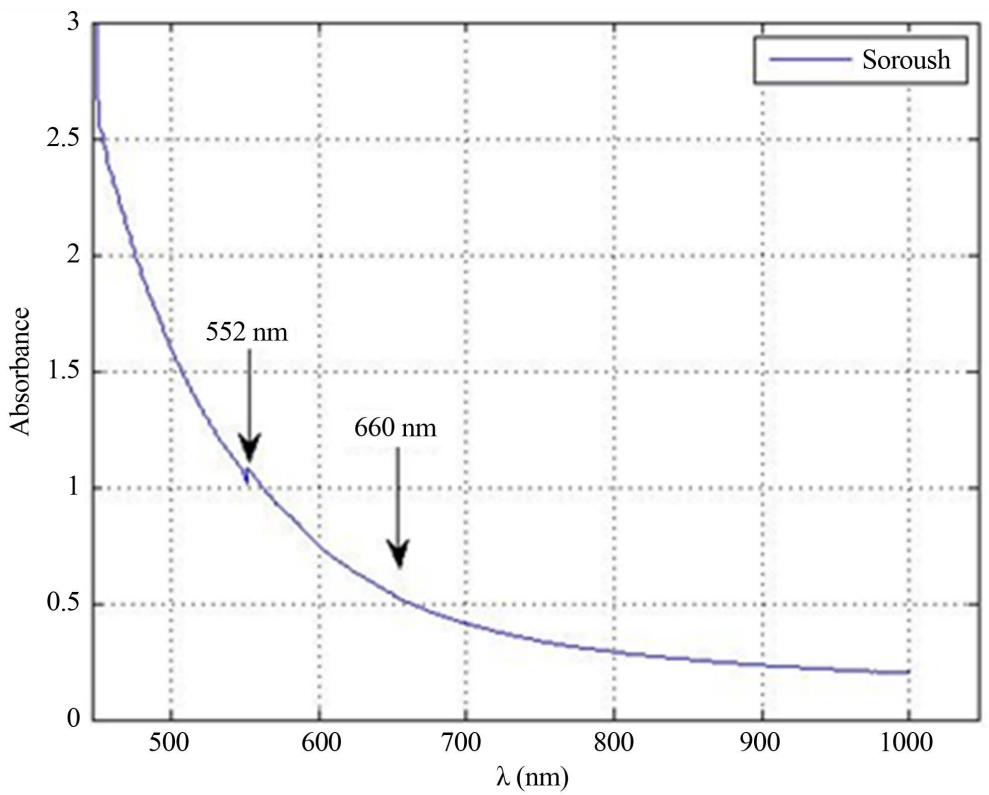

(b)

Figure 1. UV-VIS absorbance spectra. (a) Azadegan crude oil (b) Soroush crude oil.

$L=$ sample thickness

$\alpha_{0}=$ linear absorption coefficient at wavelength $\lambda$.

The nonlinear absorption coefficient $\beta$ can be obtained from this open aperture Z-scan data by fitting the normalized transmittance data to the open aperture formula given as:

$$
T(z, s=1)=\sum_{m=0}^{\infty} \frac{\left[-q_{0}(z, 0)\right]^{m}}{(m+1)^{3 / 2}}
$$

where: $q_{0}(z)=I_{0} \beta L_{\text {eff }} /\left(1+z^{2} / z_{0}^{2}\right)$ 


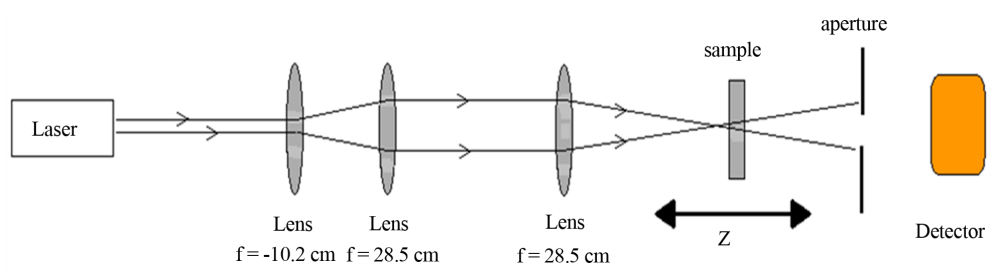

Figure 2. Experimental setup for closed aperture Z-scan.

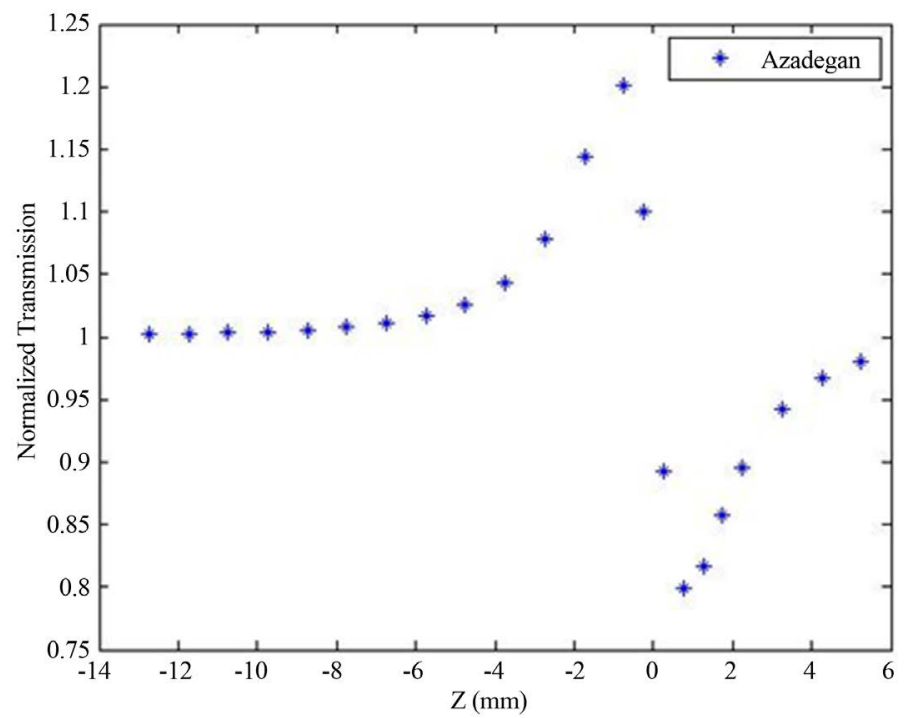

(a)

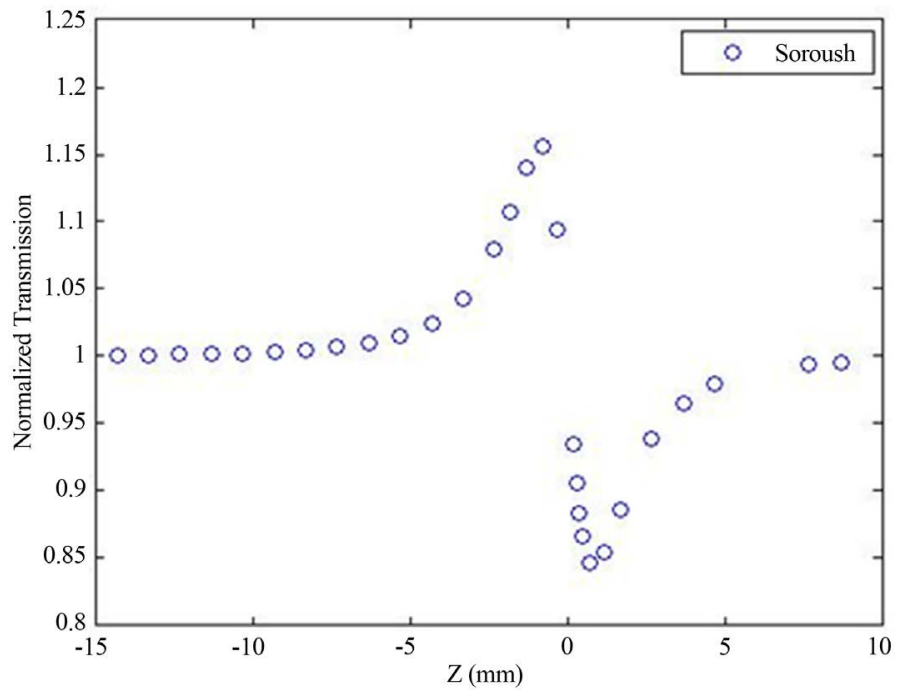

(b)

Figure 3. Normalized transmittance curve of (a) Azadegan crude oil; (b) Soroush crude oil.

$z_{0}=k w_{0}^{2} / 2$ is the diffraction length of the beam

$k=$ is the wave factor

$w_{0}=$ The beam waist radius at the focal point

The value of linear absorption coefficient and nonlinear refraction coefficients and $\Delta n_{0}$ obtained for the present samples are listed in Table 1. 
Table 1. The linear \& nonlinear optical properties of crude oils.

\begin{tabular}{cccc}
\hline Crude oil samples & $n_{2}\left(\mathrm{~cm}^{2} / \mathrm{W}\right)$ & $\Delta n_{0}$ & $\alpha\left(\mathrm{mm}^{-1}\right)$ \\
\hline Azadegan oil & $-2.2126 \mathrm{e}-008$ & $-1.4237 \mathrm{e}-004$ & 0.459 \\
Soroush oil & $-1.7116 \mathrm{e}-008$ & $-1.1014 \mathrm{e}-004$ & 0.505 \\
\hline
\end{tabular}

The results have been obtained at intensity within the sample of about $90 \mathrm{~mW}$. We find that Azadegan and Soroush crude oil samples exhibit strong self-defocusing behaviour as revealed in peak-valley shaped curves, and also peak-valley shaped curve depicts the negative sign of $n_{2}$ for crude oil samples.

\section{Conclusion}

We have carried out an investigation of the optical nonlinearity of two different crude oils from west-south Iran reservoirs Azadegan and Soroush. The nonlinear refractive index, $n_{2}$ of crude oils was measured using the single-beam z-scan technique for excitation wavelength, $660 \mathrm{~nm}$, in the $\mathrm{CW}$ regime. The sign of the nonlinear refractive was found to be negative so the experiment confirmed that the nonlinear phenomenon was caused by self-defocusing process.

\section{References}

[1] Ganeev, R.A., Ryasnyanskii, A.I., Kodirov, M.K., Kamalov, S.R., Li, V.A., Tugushev, R.I. and Usmanov, T. (2002) Technical Physics, 47, 889-893. http://dx.doi.org/10.1134/1.1495054

[2] Granmayeh Rad, A., Abbasi, H. and Golyari, K. (2012) International Journal of Applied Physics and Mathemics, 2, 135-139.

[3] Granmayeh Rad, A., Nabavi, S.H., Koohian, A. and Madanipour, Kh. (2011) Journal of Theoretical and Applied Physics, 5, 35-39

[4] Jia, T., He, T., Li, P., Mo, Y. and Cui, Y. (2008) Optics \& Laser Technology, 40, 936-940. http://dx.doi.org/10.1016/j.optlastec.2008.01.007

[5] Mukherjee, A. (1993) Applied Physics Letters, 62, 3423-3425. http://dx.doi.org/10.1063/1.109036

[6] Marder, S.R., Torrullas, W.E., Blanchard-Desce, M., Ricci, V., Stegman, G.I., Gilmour, S., Bredas, J.L., Li, J., Bublitz, G.U. and Boxer, S.G. (1997) Science, 276, 1233-1236. http://dx.doi.org/10.1126/science.276.5316.1233

[7] Li, C., Zhang, L., Yang, M., Wang, H. and Wang Y. (1994) Physical Review A, 49, 1149-1157. http://dx.doi.org/10.1103/PhysRevA.49.1149

[8] Guo, S.L., Xu, L., Wang, H.T., You, X.Z. and Ming, N.B. (2003) Optical and Quantum Electronics, 35, $693-703$. http://dx.doi.org/10.1023/A:1023981924486

[9] Sheik-Bahaei, M., Said, A.A. and Van Stryland, E.W. (1989) Optics InfoBase: Optics Letters, 14, 955-957. http://dx.doi.org/10.1364/OL.14.000955

[10] Sheik-Bahaei, M. and Van Stryland, E.W. (1998) Z-Scan Measurements of Optical Nonlinearities, Characterization Techniques and Tabulations for Organic Nonlinear Materials. In: Kuzyk, M.G. and Dirk, C.W., Eds., Marcel Dekker, Inc., 655-692.

[11] Ménard, J.M., Betz, M., Sigal, I. and van Driel, H.M. (2007) Applied Optics, 46, 2119-2122. http://dx.doi.org/10.1364/AO.46.002119 